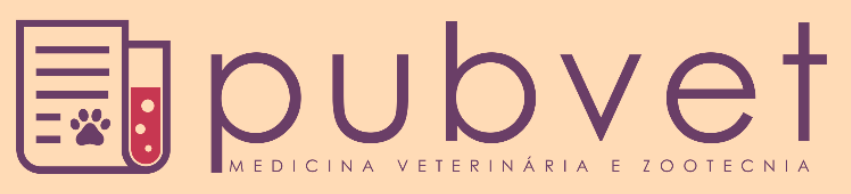

https://doi.org/10.31533/pubvet.v14n6a597.1-5

\title{
Sexagem de aves da espécie Amazona aestiva (Papagaio Verdadeiro) pela técnica de PCR
}

Fabiana Batalha Knackfuss ${ }^{1} \oplus$, Danielle Dutra Voigt $^{2} \theta$, Ricardo Silva Novaes ${ }^{3} \theta$, Samira Domett Carmo da Silva ${ }^{4}$, Luara Duarte dos Santos Nascimento ${ }^{4} \bullet$, Janaina Cristina Furtado de Albuquerque $^{40}$, Vivianne Galante $\operatorname{Ramos}^{10}$, Renato Luiz Silveira ${ }^{\circ}$

${ }^{I}$ Professor(a) Adjunto Escola de Ciências da Saúde - Universidade do Grande Rio.

${ }^{2}$ Biomédical Preceptora do laboratório de Genética da Universidade Unigranrio (LabGen).

${ }^{3}$ Médico Veterinário-Responsável Técnico Criadouro Passaredo.

${ }^{4}$ Aluna do Curso de Graduação em Medicina Veterinária - Universidade do Grande Rio.

${ }_{5}^{5}$ Professor Associado do Departamento de Morfologia - Universidade Federal Fluminense.

*Autor correspondente, E-mail: KnackfussFB@Unigranrio.edu.br

Resumo. Na maioria das espécies de aves não é possível realizar a identificação do gênero pelas características fenotípicas externas já que os órgãos reprodutivos são internos. Sendo assim, como é fundamental para os criadores realizar esta diferenciação sexual não apenas pela reprodução mas também pelo fato que em algumas espécies apenas os machos manifestam certas características como o canto, é extremamente importante realizar a sexagem de aves por meio da análise do DNA, que além de conferir 99,9\% de confiabilidade ao resultado, traz outras vantagens em relação a outras técnicas, como a diminuição do estresse e do risco de danos à ave e também o fato de ser aplicado a partir de qualquer idade (ideal para os filhotes). O objetivo deste trabalho foi realizar a sexagem de 13 aves da espécie de Amazona aestiva (Papagaio-Verdadeiro) por meio da técnica de PCR (Reação em Cadeia de Polimerase). Já que nas aves o sexo heterogamético é o das fêmeas, duas bandas foram observadas para este sexo e apenas uma foi observada para o masculino, sendo identificados 5 machos e 3 fêmeas. A partir dos resultados obtidos foi possível concluir que a técnica de PCR permitiu identificar o sexo dos animais de forma eficaz e pouco invasiva representando uma importante ferramenta para o direcionamento de acasalamentos e conservação da espécie de aves silvestres.

Palavras chave: Amazona aestiva, $\mathrm{CHD}$, sexagem, PCR

\section{Sexing of birds of Amazona aestiva (True Parrot) using PCR technique}

\begin{abstract}
In most species of birds, it is not possible to identify the genus by the external phenotypic characteristics in young animals since the reproductive organs are internal. Therefore, as it is fundamental for breeders to carry out this sexual differentiation not only for the reproductive issue but also for the fact that in some species only males show certain characteristics such as song, it is extremely important to perform the sexing of birds through DNA analysis, which besides giving $99.9 \%$ reliability to the result, brings other advantages in relation to other techniques, such as the reduction of stress and the risk of damage to the bird and also the fact that it is applied from any age (ideal for the chicks). The objective of this work was to sex 13 birds of the species of Amazon aestiva (Papagaio-Verdadeiro) using the PCR technique. Since in birds the heterogametic sex is that of females, two bands were observed for this genus and only one was observed for males, with 5 males and 3 females being identified. From the results obtained it was possible to conclude that the PCR technique allowed to confirm the animals' genus in an efficient and non-invasive way, representing an important tool for targeting mating and conservation of the wild bird species.
\end{abstract}

Keywords: Amazona aestiva, CHD, sexing, PCR 


\section{Sexado de aves de la especie Amazon aestiva (True Parrot) utilizando la técnica de PCR}

Resumen. En la mayoría de las especies de aves, no es posible identificar el género por características fenotípicas externas ya que los órganos reproductivos son internos. Por lo tanto, como es fundamental para los criadores hacer esta diferenciación sexual no solo por reproducción sino también por el hecho de que en algunas especies solo los machos muestran ciertas características como el canto, es extremadamente importante realizar el sexado de las aves a través del análisis de ADN, lo que, además de proporcionar un 99.9\% de confiabilidad al resultado, brinda otras ventajas sobre otras técnicas, como la reducción del estrés y el riesgo de daños al ave y también el hecho de que se aplica desde cualquier edad (ideal para polluelos). El objetivo de este trabajo fue sexar 13 aves de la especie de Amazon aestiva (True Parrot) utilizando la técnica PCR (reacción en cadena de la polimerasa). Dado que en las aves el sexo heterogamético es el de las hembras, se observaron dos bandas para este sexo y solo se observó una para los machos, con 5 machos y 3 hembras identificadas. A partir de los resultados obtenidos, fue posible concluir que la técnica de PCR permitió identificar el sexo de los animales de manera eficiente y no invasiva, lo que representa una herramienta importante para abordar el apareamiento y la conservación de las especies de aves silvestres.

Palabras clave: Amazona aestiva, CHD, PCR, sexado

\section{Introdução}

Algumas espécies de aves não apresentam dimorfismo sexual evidente, tornando a determinação sexual baseada apenas em características anátomo-morfológicas (Griffiths, 2000). Entretanto, para a maioria das aves, os órgãos sexuais são internos ao corpo do animal, de forma que nos jovens se torna muito difícil a diferenciação sexual, que nas aves silvestres especialmente é extremamente importante principalmente para estudos de conservação e manejo ambiental (Rudnick et al, 2005).

Um dos métodos mais recomendados ultimamente tem sido a técnica de PCR por ser de custo relativamente baixo e efetivamente pode distinguir os machos das fêmeas em qualquer estágio de desenvolvimento. Além disto, a identificação do sexo pelo DNA confere $99,9 \%$ de certeza ao diagnóstico, precisão não alcançada por técnicas de natureza mecânica não causando estresse e nem lesões no animal, pois são necessários apenas uma ínfima quantidade de sangue ou penas para a análise Miyaki et al. (1998).

Nas aves o sexo é determinado por cromossomos sexuais $\mathrm{Z}$ e W (Waldrigues, 1982). A região do genoma relacionada ao controle da transcrição de genes de desenvolvimento sexual, denominada CHD (chromo-helicase-DNA-binding, helicase dependente de cromo) (Ellergren, 1996) pode ser amplificada pelo método da Reação em Cadeia da Polimerase (PCR) (Morinha et al., 2012) utilizando-se uma dupla de primers P2/P8 (CHD-universal) que amplifica fragmentos homólogos de ambos os genes específicos e permitindo uma clara separação sexual. As fêmeas, sexo heterogamético em aves, possuem um cromossomo Z e um W, já os machos possuem dois cromossomos Z (Fridolfsson \& Ellegren, 2000). O gene CHD-W localiza-se no cromossomo W, sendo único nas fêmeas e o CHD-Z encontra-se no cromossomo Z, ocorrendo em ambos os sexos (Griffiths et al., 1998). Pela aplicação da técnica de PCR amplificam-se seções homólogas dos dois genes e incorporam-se íntrons, os quais variam de tamanho sendo o resultado analisado pelo padrão de bandas observadas em géis de agarose: o macho apresenta uma banda, enquanto as fêmeas apresentam duas (Griffiths et al., 1998).

O papagaio-verdadeiro (Amazona aestiva (Linnaeus, 1758)) tem a fama de ser o melhor falador e, por isso, é uma das aves de estimação de maior procura no país, além disso, é uma das espécies alvo do tráfico de animais silvestres. Sendo assim, o presente trabalho teve como objetivo realizar a identificação sexual de aves da espécie Amazona aestiva (Papagaio-verdadeiro) utilizando-se amostras de sangue para a realização da extração de DNA e posterior amplificação com primers específicos para o gene CHD, localizado nos cromossomos sexuais $\mathrm{Z}$ e W. 


\section{Material e métodos}

Amostras de sangue de 13 aves da espécie Amazona aestiva do criadouro Passaredo, localizado em Guaratiba - Rio de Janeiro - RJ foram coletadas com papel de filtro (Marca Whatman, $55 \mathrm{~mm}$ ) por meio do corte da unha e armazenadas em envelope. Todos os animais apresentavam número de registro no IBAMA e os dados foram previamente submetidos e aprovados pela CEUA/UNIGRANRIO ( ${ }^{\circ}$ 020/2019).

No laboratório LabGen (UNIGRANRIO), as amostras foram armazenadas individualmente e devidamente identificadas pelo número da anilha. O DNA das amostras foi extraído com o kit comercial PureLin $^{k @}$ (Invitrogen, Carlsbad, CA, EUA) de acordo com o protocolo sugerido pelo próprio fabricante e posteriormente a qualidade e concentração do DNA foram avaliadas por espectrofotometria em equipamento Nanodrop (Thermo Scientific, Wilmington, DE, EUA), com leitura da absorbância nos comprimentos de ondas A260 e A280.

O par de primers utilizado neste trabalho (P2 e P8) se liga a duas regioes de éxons conservadas, flanqueando uma região de íntron (Jensen et al., 2003). As bandas resultantes da amplificação dos alelos $\mathrm{Z}$ e W (de papagaio) utilizando-se os esses iniciadores apresentam tamanhos proximos, com o alelo Z próximo a $396 \mathrm{pb}$ (pares de bases) e o alelo $\mathrm{W}$ cerca de $412 \mathrm{pb}$.

Foi realizado um gradiente de concentração no qual foram testadas temperaturas de anelamento que variaram de 39 a $49^{\circ} \mathrm{C}$. A padronização da PCR ocorreu nas seguintes condições de protocolo: $2,5 \mu \mathrm{L}$ de tampão, 2,5 $\mu \mathrm{L}$ de $\mathrm{MgCl} 2,1,5 \mu \mathrm{L}$ de dNTP, $0,5 \mu \mathrm{L}$ de iniciador Foward P2 (5' TCTGCATCGCTAAATCCTTT - $\left.3^{\prime}\right), \quad 0,5 \mu \mathrm{L}$ de iniciador Reverso P8 (5' CTCCCAAGGATGAGRAAYTG - 3'- Griffiths et. al., 1998), 0,5 $\mu \mathrm{L}$ de Taq Polimerase, $2,0 \mu \mathrm{L}$ de DNA e $15,0 \mu \mathrm{L}$ de $\mathrm{H} 2 \mathrm{O}$, totalizando volume de $25,0 \mu \mathrm{L}$ por amostra. As condições de Ciclagem consistiram em desnaturação Inicial de $95^{\circ} \mathrm{C}$ por 5 minutos seguida por $95^{\circ} \mathrm{C}$ por 1 minuto, $41^{\circ} \mathrm{C}$ por 15 segundos, $72^{\circ} \mathrm{C}$ por 40 segundos $\left(35\right.$ ciclos) e etapa final a $72^{\circ} \mathrm{C}$ por 7 minutos. Os produtos amplificados foram submetidos a eletroforese em gel de Agarose 1,5\% e posteriormente avaliadas no transiluminador para avaliação do resultado.

\section{Resultados e discussão}

O sucesso dos programas de conservação de aves está relacionado à correta e identificação sexual. Estima-se que aproximadamente $30 \%$ dos pássaros do mundo sejam monomórficas, ou seja, não apresentam dimorfismo sexual externo e, quando ocorre, geralmente as diferenças são sutis e expressas apenas no período de maturidade sexual (Vieira et al, 2009). A família Psittacidae (que inclui a espécie A. aestiva) é uma das que apresenta maior de espécies que não exibem dimorfismo sexual, o que reforça a importância de métodos eficazes e precoces de determinação sexual.

Cinco amostras do total não foram amplificadas com sucesso, provavelmente pela pequena quantidade de sangue coletado. Para as oito amostras restantes o método de sexagem usando o par de primers $\mathrm{P} 2 / \mathrm{P} 8$ obteve resultado positivo nas amostras de A. aestiva, confirmando os dados propostos por Griffiths et al. (1998) que afirmaram que este par de primers é único, robusto e universal sendo eficaz na diferenciação sexual das aves. Entretanto, estes autores sugeriram uma temperatura de anelamento de $48 \pm 3^{\circ} \mathrm{C}$ para todas as espécies de aves, o que não foi verificado neste estudo uma vez que a temperatura ideal de amplificação foi de $41^{\circ} \mathrm{C}$, corroborando com os protocolos utilizados por Turci et al. (2004) para o gênero Amazona e Miyaki et al. (1997) para psitacídeos em geral.

A interpretação das amostras amplificadas foi feita de acordo com o genótipo de fêmeas que são heterogaméticas (ZW) apresentando dois alelos (396/412) no gel, ou seja, heterozigotas e dos machos que são homogaméticos (ZZ), apresentando apenas um alelo (412), sendo, portanto, homozigotos (Figura 1). Estes resultados concordam com os obtidos por outros autores, como por Griffiths et al. (1998), Miyaki et al. (1998), Purwaningrum et al. (2019), Santos et al. (2006), Vieira et al. (2009) e Vieira et al. (2010) que também obtiveram eficiente amplificação e diferenciação alélica utilizando os primers utilizados neste estudo. 


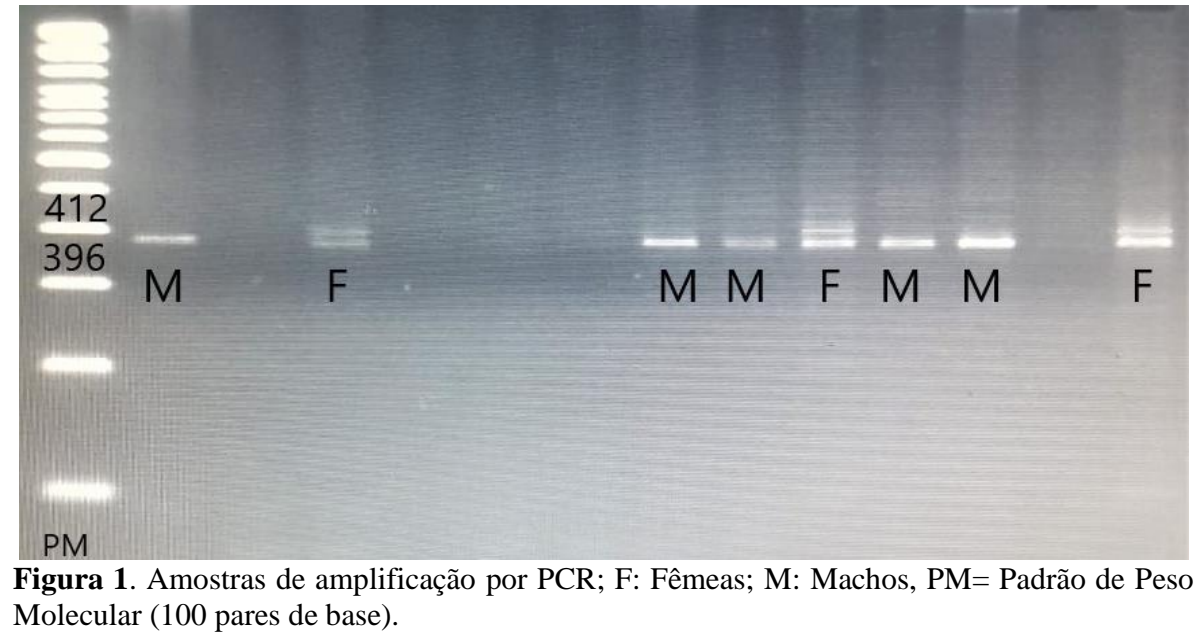

\section{Conclusões}

A partir do padrão alélico obtido foi possível concluir que a técnica de PCR permitiu a identificação sexual dos animais de forma eficaz, rápida, sensível, pouco invasiva e dependente de pequena amostra de DNA em animais da espécie Amazona aestiva representando uma importante ferramenta para o direcionamento de acasalamentos e conservação da espécie de aves silvestres.

\section{Referências bibliográficas}

Ellergren, H. (1996). First gene on the avian W chromosome (CHD) provides a tag for universal sexing of non-ratite birds. Proceedings of the Royal Society, 263(1377), 1635-1641. DOI: https://doi.org/10.1098/rspb.1996.0239

Fridolfsson A. K. \& Ellegren H. (1999). A simple and universal method for molecular sexing of nonratite birds Journal of Avian Biology, 30(1), 116-121. DOI: 10.2307/3677252

Griffiths, R., Double M. C, Orr, K. \& Dawson R.J. (1998). A DNA test to sex most birds. Molecular Ecology,7(8), 1071-1075. DOI: https://doi.org/10.1046/j.1365-294x.1998.00389.x

Griffiths, R. (2000). Sex Identification in Birds. Seminars in Avian and Exotic Pet Medicine, 9(1), 1426. DOI: https://doi.org/10.1016/S1055-937X(00)80012-2

Jensen, T., F. Persanetti, M. \& Durrant, B. (2003). Conditions for Rapid Sex Determination in 47 Avian Species by PCR of Genomic DNA From Blood, Shell-Membrane Blood Vessels, and Feathers. Zoo Biology 22, 561-571. DOI: https://doi.org/10.1002/zoo.10101

Miyaki, C. Y., Duarte, M. B., Caparroz, R., Nunes, A. L. V. \& Wajntal, A. (1997). Sex identification of South American parrots (Psittacidae, aves): using the human minisatellite probe 33.15. The Auk, 114(3), 516-520. DOI: 10.2307/4089258

Miyaki, C. Y., Griffiths, R., Orr, K., Nahum, L. A., Pereira, S. L., \& Wajntal, A. (1998). Sex identification of parrots, toucans, and curassows by PCR: perspectives for wild and captive population studies. Zoo Biology, 17, 415-423. DOI: https://doi.org/10.1002/(SICI)10982361(1998)17:5\%3C415::AID-ZOO6\%3E3.0.CO;2-2

Morinha F, Cabral J. A. \& Bastos E. (2012). Molecular sexing of birds: A comparative review of polymerase chain reaction (PCR)-based methods. Theriogenology, 78(4), 703-714. DOI: https://doi.org/10.1016/j.theriogenology.2012.04.015

Purwaningrum, M., Nugroho, H. A., Asvan, M., Karyanti, K., Alviyanto, B., Kusuma, R., \& Haryanto, A. (2019). Molecular techniques for sex identification of captive birds. Veterinary world, 12(9), 1506-1513. https://doi.org/10.14202/vetworld.2019.1506-1513

Rudnick, J. A., Katzner, T. E., Bragin, E.A., Rhodes Júnior, O. E. \& DeWoody, J.A. (2005). Using naturally shed feathers for individual identification, genetic parentage analyses, and population monitoring in an endangered Eastern imperial eagle (Aquila heliaca) population from Kazakhstan. Molecular Ecology,14, 2959-2967. DOI: https://doi.org/10.1111/j.1365-294X.2005.02641.x 
Santos, S. I. C. O., Elward, B. \& Lumeij, J. T. (2006). Sexual dichromatism in the blue-fronted Amazon parrot (Amazona aestiva) revealed by multipli-angle spectrometry. Journal of Avian Medicine and Surgery, 20(1), 8-14. DOI: https://doi.org/10.1647/1082-6742(2006)20[8:SDITBA]2.0.CO;2

Turci, K.F., Nóbrega, F.G., Moral, F. A. F. (2004). Identificação sexual para formação de casais de espécies do gênero Amazona (Psittacidae, Aves) pertencentes ao criadouro conservacionista UNIVAP. VIII Encontro Latino Americano de Iniciação Cientifica e IV Encontro Latino Americano de Pós-Graduação - Universidade do Vale do Paraíba, 119-123.et al.

Vieira, J. N., Coelho, E. G. A. \& Oliveira, D. A. A. (2010). Comparação de três técnicas de extração de DNA para sexagem molecular em aves. Veterinária e Zootecnia, 17(3), 394-398.

Vieira, J. N., Coelho, E. G. A. \& Oliveira, D. A. A. (2009). Sexagem Molecular em aves silvestres [Molecular sexing in wild birds]. Revista Brasileira de Reprodução Animal, 33(2), 66- 70.

Waldrigues, A. (1982). Citogenetica de Aves. IV Citotaxonomia e Evolução. Semina, 3(11): 16-172.

Recebido: 1 de maio, 2020 .

Aprovado: 29 de maio, 2020.

Disponível online: 18 julho, 2020.

Licenciamento: Este artigo é publicado na modalidade Acesso Aberto sob a licença Creative Commons Atribuição 4.0 (CC-BY 4.0), a qual permite uso irrestrito, distribuição, reprodução em qualquer meio, desde que o autor e a fonte sejam devidamente creditados 